2003s-12

\title{
Disentangling Risk Aversion and Intertemporal Substitution Through a Reference Level
}

René Garcia, Éric Renault, Andrei Semenov

\section{Série Scientifique \\ Scientific Series}

\section{Montréal}

Avril 2003

(C) 2003 René Garcia, Éric Renault, Andrei Semenov. Tous droits réservés. All rights reserved. Reproduction partielle permise avec citation du document source, incluant la notice $@$.

Short sections may be quoted without explicit permission, if full credit, including $@$ notice, is given to the source.
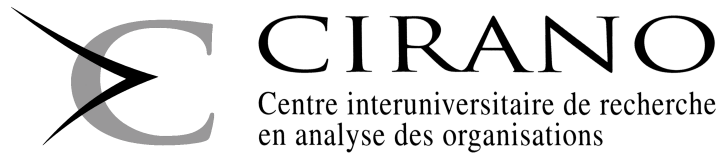

Centre interuniversitaire de recherche en analyse des organisations 


\section{CIRANO}

Le CIRANO est un organisme sans but lucratif constitué en vertu de la Loi des compagnies du Québec. Le financement de son infrastructure et de ses activités de recherche provient des cotisations de ses organisationsmembres, d'une subvention d'infrastructure du ministère de la Recherche, de la Science et de la Technologie, de même que des subventions et mandats obtenus par ses équipes de recherche.

CIRANO is a private non-profit organization incorporated under the Québec Companies Act. Its infrastructure and research activities are funded through fees paid by member organizations, an infrastructure grant from the Ministère de la Recherche, de la Science et de la Technologie, and grants and research mandates obtained by its research teams.

\section{Les organisations-partenaires / The Partner Organizations}

PARTENAIRE MAJEUR

. Ministère des Finances, de l'Économie et de la Recherche [MFER]

PARTENAIRES

. Alcan inc.

. Axa Canada

. Banque du Canada

. Banque Laurentienne du Canada

. Banque Nationale du Canada

. Banque Royale du Canada

. Bell Canada

. Bombardier

. Bourse de Montréal

. Développement des ressources humaines Canada [DRHC]

. Fédération des caisses Desjardins du Québec

. Gaz Métropolitain

. Hydro-Québec

. Industrie Canada

. Pratt \& Whitney Canada Inc.

. Raymond Chabot Grant Thornton

. Ville de Montréal

. École Polytechnique de Montréal

. HEC Montréal

. Université Concordia

. Université de Montréal

. Université du Québec à Montréal

. Université Laval

. Université McGill

ASSOCIÉ AU :

. Institut de Finance Mathématique de Montréal (IFM²)

. Laboratoires universitaires Bell Canada

. Réseau de calcul et de modélisation mathématique $\left[\mathrm{RCM}^{2}\right]$

. Réseau de centres d'excellence MITACS (Les mathématiques des technologies de l'information et des systèmes complexes)

Les cahiers de la série scientifique (CS) visent à rendre accessibles des résultats de recherche effectuée au CIRANO afin de susciter échanges et commentaires. Ces cahiers sont écrits dans le style des publications scientifiques. Les idées et les opinions émises sont sous l'unique responsabilité des auteurs et ne représentent pas nécessairement les positions du CIRANO ou de ses partenaires.

This paper presents research carried out at CIRANO and aims at encouraging discussion and comment. The observations and viewpoints expressed are the sole responsibility of the authors. They do not necessarily represent positions of CIRANO or its partners. 


\title{
Disentangling Risk Aversion and Intertemporal Substitution Through a Reference Level*
}

\author{
René Garcia ${ }^{\dagger}$ Éric Renault ${ }^{\ddagger}$ Andrei Semenov ${ }^{\S}$
}

\section{Résumé / Abstract}

Dans le modèle standard d'évaluation des actifs financiers fondé sur la consommation (CCAPM), la courbure de la fonction d'utilité de l'investisseur associe deux aspects des préférences: l'aversion pour le risque et le désir de lisser la consommation intertemporellement augmentent proportionnellement avec la concavité de la fonction. Cette association n'est ni justifiée théoriquement ni vérifiée empiriquement. Pour séparer les deux concepts, Epstein et Zin (1989) et Weil (1989) ont proposé un cadre fondé sur l'utilité récursive. Toutefois, la mesure d'aversion pour le risque $(1-\alpha)$ qui en résulte ne doit pas être considérée comme un simple indice d'Arrow-Pratt d'aversion relative pour le risque qui pourrait s'interpréter indépendamment du niveau de l'élasticité $\sigma$. Cette absence de séparation vient du fait que le modèle d'utilité récursive introduit l'aversion pour le risque en définissant un équivalent certain de l'utilité future qui mélange les attitudes à l'égard du risque et de la substitution intertemporelle. Nous montrons que plus $\sigma$ est élevée (tout en restant inférieure à un pour rester réaliste), plus $(1-\alpha)$ sousestime le niveau véritable de l'aversion pour le risque car un $\sigma$ élevé facilite la diversification intertemporelle et donc réduit subtantiellement le niveau de risque effectivement supporté. Nous proposons de réaliser la séparation désirée en introduisant un niveau de référence exogène qui, de manière récursive, évalue la consommation future attendue. Par conséquent, l'aversion pour le risque se définit à présent par rapport à l'écart imprévisible entre la consommation effective et ce niveau de référence (une quantité indépendante de l'attitude à l'égard du risque). Dans ce nouveau cadre, les préférences sont représentées par une spécification généralisée de l'utilité von Neumann-Morgenstern selon laquelle la satisfaction résulte à la fois de la consommation relativement à un niveau de référence externe et du niveau de référence proprement dit.

Mots-clés : aversion pour le risque, substitution intertemporelle, utilité récursive, niveau de référence, séparation des préférences.

\footnotetext{
* The authors gratefully acknowledge financial support from the Fonds de la Formation de Chercheurs et l'Aide à la Recherche du Québec (FCAR), the Social Sciences and Humanities Research Council of Canada (SSHRC), the Network of Centres of Excellence MITACS and the Institut de Finance Mathématique de Montréal (IFM2).

$\dagger$ Economics Department, Université de Montréal, CIRANO and CIREQ: Corresponding Author: Département de Sciences Économiques et CIREQ, Université de Montréal, C.P. 6128, Succursale Centre-Ville, Montréal, Québec, H3C 3J7, Canada. ¥ CIRANO and CIREQ, Université de Montréal. $\S$ CIRANO and CIREQ, Université de Montréal.
} 
In the standard consumption capital asset pricing model (CCAPM), the curvature of the investor's utility function captures two aspects of preferences: as the concavity of the function increases so does his aversion to risk as well as his desire to smooth consumption intertemporally. This restriction is not theoretically justified nor empirically supported. To disentangle the two concepts, Epstein and Zin (1989) and Weil (1989) have proposed a recursive utility framework. However, the ensuing risk aversion measure $(1-\alpha)$ should not be considered as a simple Arrow-Pratt index of relative risk aversion that could be interpreted independently of the level of the elasticity $\sigma$. The lack of disentangling comes from the fact that the recursive utility model introduces risk aversion through the definition of a certainty equivalent of future utility that mixes attitudes towards risk and intertemporal substitution. We show that the higher $\sigma$ is (while remaining smaller than one to be realistic), the more $(1-\alpha)$ underestimates the genuine level of risk aversion since a higher $\sigma$ facilitates intertemporal diversification and thus substantially lowers the level of risk that is significantly borne. We suggest that the requested disentangling may alternatively be obtained by introducing an exogenous reference level which, in a recursive way, assesses the expected future consumption. Therefore, risk aversion is now defined with respect to the unpredictable discrepancy between actual consumption and this reference level (a quantity independent of the attitude towards risk). In this new framework, preferences are represented by a generalized von Neumann-Morgenstern utility specification whereby satisfaction is derived from consumption relative to an external reference level as well as from this reference level itself.

Keywords: Risk aversion, Intertemporal substitution, Recursive utility, Reference Level, Disentangling preferences. 


\section{Introduction}

In the standard consumption capital asset pricing model (CCAPM), a representative agent maximizes his time-separable expected utility. The curvature of the utility function captures two aspects of the agent's preferences. As the concavity of the function increases so does his aversion to risk as well as his desire to smooth consumption intertemporally. For a power utility function, it means that the coefficient of relative risk aversion is constrained to be the inverse of the elasticity of intertemporal substitution. This constraint is not supported by empirical observations since agents tend to exhibit an elasticity of intertemporal substitution which is less than the inverse of the relative risk aversion coefficient, as emphasized in Weil (1990). To disentangle the two concepts, Epstein and Zin (1989), often referred to as EZ hereafer, and Weil (1989) have proposed a recursive utility framework that generalizes the dynamic choice model under uncertainty of Kreps and Porteus (1978).

Epstein and Zin (1989) qualify this disentangling by stressing that the risk aversion parameter in their model should not be interpreted independently from the attitude towards intertemporal substitution. However, after reading Epstein and Zin (1991) and a number of papers in the ensuing literature, one realizes that the estimates of the risk aversion parameter are often directly compared with the ones obtained in the standard CCAPM framework as in Hansen and Singleton (1983). We will argue that such a reading of the risk parameter in the Epstein-Zin model could lead to spurious interpretations of alledgedly realistic low levels of estimated risk aversion. Moreover, Epstein and Zin's (1991) conclusion that "risk preferences do not differ statistically from the logarithmic specification" could be reinterpreted as an indication that the attitude towards intertemporal substitution does not differ statistically from the logarithmic specification. This reinterpretation is crucially important from an economic point of view since it allows to distinguish myopia in consumption-saving decisions from myopia in portfolio allocation (Giovannini and Weil, 1989).

In this paper, we propose a new way to extend preferences to uncertain future consumption flows while maintaining the same unambiguous definition of the elasticity of intertemporal substitution for certain future streams of consumption. We suggest that the requested disentangling may alternatively be obtained not by replacing, as the recursive utility does, the future consumption stream by a certainty equivalent of future utility but by an exogenous reference level which, in a recursive way, assesses the expected future consumption. Therefore, risk aversion is now defined with respect to the unpredictable discrepancy between actual consumption and this reference level (a quantity independent of the attitude towards risk) and not with respect to the forthcoming level of recursive utility which still mixes attitudes towards risk and intertemporal substitution. 
In this new framework, preferences are therefore represented by a generalized von Neumann-Morgenstern utility specification whereby satisfaction is derived from consumption relative to an external reference level as well as from this reference level itself. This specification is related to several concepts in the literature. In habit formation models, utility is measured with respect to consumption relative to a time-varying habit or subsistence level either in ratios (Abel, 1990, 1996) or in differences (Constantinides,1990, Sundaresan, 1989 and Campbell and Cochrane, 1999), among others. Several variables have also been added to the utility function besides consumption: leisure (Eichenbaum, Hansen and Singleton (1988), public expenditures (Aschauer,1985), durable goods (Startz,1989), wealth (Bakshi and Chen, 1996, Smith, 2001). Recently, Carroll, Overland, and Weil (2000), in a growth and saving model, proposed a specification in which the agent can derive utility both from the level of consumption relative to a reference level and from the absolute value of this reference level.

To recover a stochastic discount factor (SDF) which is observationally equivalent to the Kreps and Porteus specification in the recursive utility framework of Epstein and Zin (1989), as we do in this paper, we establish a structural link between this reference level and the return on the market portfolio. However, we emphasize that, although observationally equivalent, the two models deliver different measures of risk aversion. As in Barberis, Huang and Santos (2001), the introduction of a reference level actually changes the measure of risk and in turn the level of risk aversion needed to explain the observed risk premium. ${ }^{1}$ In Garcia, Renault and Semenov (2002), henceforth GRS (2002), we generalize the reference level and make it depend on past consumption as well as on the return on the market portfolio. Therefore, we embed both habit persistence and the recursive utility KrepsPorteus model in the same SDF.

Section 2 presents the issue of disentangling risk aversion from the elasticity of intertemporal substitution in a recursive utility framework. In section 3, we introduce a new von Neumann-Morgenstern expected utility framework which provides a better separation of the two concepts. In particular, we show in this context that the risk aversion parameter in the recursive utility specification depends on the intertemporal elasticity of substitution. Section 4 concludes.

\footnotetext{
${ }^{1}$ This result does not depend upon any specific behavioral interpretation of the reference level and may simply be produced by the heterogeneity of agents as in Guvenen (2002).
} 


\section{Disentangling Risk Aversion and Intertemporal Substitution via Recursive Utility}

Our focus of interest is the modelling of a preference ordering between stochastic consumption processes $C=\left(C_{t}\right)_{t \geq 0}$. Following Duffie and Epstein (1992a), it is quite natural to consider that a utility function $U$ is risk averse if, for all processes $C$ in some domain:

$$
U[C] \leq U[E C]
$$

where $E C$ denotes the deterministic process defined by $[E(C)]_{t}=E\left[C_{t}\right]$. A more difficult question is to assess the level of risk aversion of a given utility function $U$ in this intertemporal context. Yet, an answer to this question is crucial for contributing to the empirical debate surrounding asset pricing puzzles. For instance, the equity premium puzzle amounts to consider that the level of risk aversion needed to reproduce the observed risk premium on equity is not reasonable. One step in the direction of quantifying risk aversion has been performed by Duffie and Epstein (1992a) through the notion of comparative risk aversion. They define this concept as follows.

Definition 1 A utility function $U^{*}$ is said to be more risk averse than $U$ if it rejects any gamble that is rejected by $U$, that is for any stochastic process $C$ and any deterministic process $\bar{C}$ in some domain: $U[C] \leq U[\bar{C}] \Longrightarrow U^{*}[C] \leq U^{*}[\bar{C}]$.

In other words, if $U$ leads to prefer a deterministic sequence $\bar{C}_{t}, t \geq 0$, to a stochastic consumption process $C_{t}, t \geq 0$, a fortiori $U^{*}$ will lead to prefer the deterministic path. As acknowledged by Duffie and Epstein (1992a), this definition is not innocuous. To be comparable according to this definition, $U^{*}$ and $U$ must rank deterministic programs identically.

In particular, one cannot give a sense to the statement " $U^{*}$ is more risk averse than $U$ " if $U^{*}$ and $U$ feature different temporal preferences, either for immediate versus late consumption (subjective discounting) or for consumption smoothing (elasticity of intertemporal substitution). This is indeed a fundamental impossibility result about disentangling risk aversion and intertemporal substitution. The only way to escape this general impossibility is to be more specific about the utility model. Epstein and Zin (1989) and Duffie and Epstein (1992 a,b) put forward the recursive utility framework in discrete time and continuous time respectively.

First introduced by Koopmans (1960) in a deterministic setting, the recursive relation:

$$
V_{t}=W\left[C_{t}, V_{t+1}\right]
$$


specifies the utility index $V_{t}$ at time $t$ as a function of the consumption $C_{t}$ in period $t$ and the utility index $V_{t+1}$ of future consumption. The function $W$ has been called an aggregator by Lucas and Stokey (1984). It defines both the rate of time preference and the elasticity of intertemporal substitution. For instance, the time-additive separable (TAS) utility function ${ }^{2}$ corresponds to the aggregator:

$$
W[C, V]=u(C)+\beta V
$$

where $\beta$ is the subjective discount factor. In the isoelastic case, $u(C)=\frac{C^{\rho}-1}{\rho}, \rho \leq 1, \rho=$ $1-\frac{1}{\sigma}, \sigma>0$ is the elasticity of intertemporal substitution. The issue of interest is to extend equation (2.1) to uncertain consumption streams. Then, the future utility index $V_{t+1}$ appears itself random at time $t$ (we will denote it $\widetilde{V}_{t+1}$ to stress that it is stochastic) and cannot be plugged into (2.1) without a preliminary treatment.

In other words, we must look for a generalization of (2.1) which admits the latter equation as a particular case when the future random value of $\widetilde{V}_{t+1}$ is known at time $t$. The solution proposed by Epstein and Zin (1989) appears to be quite natural in this respect. They consider that the agent first computes the certainty equivalent $m\left(\widetilde{V}_{t+1} \mid I_{t}\right)$ of the conditional distribution $\left(\widetilde{V}_{t+1} \mid I_{t}\right)$ of $\widetilde{V}_{t+1}$ given the information at time $t$ and then combines the latter with $C_{t}$ via the aggregator $W$ :

$$
V_{t}=W\left[C_{t}, m\left(\widetilde{V}_{t+1} \mid I_{t}\right)\right]
$$

They refer to Kreps and Porteus (1978) to study (2.3) under the assumption that $m$ is an expected-utility based certainty equivalent such as:

$$
m\left(\widetilde{V}_{t+1} \mid I_{t}\right)=f^{-1}\left[E\left[f\left(\widetilde{V}_{t+1}\right) \mid I_{t}\right]\right]
$$

where they call $f$ a von Neumann-Morgenstern utility index.

This terminology is motivated by the fact that the utility functions defined by (2.3) and (2.4) conform with expected utility theory when ranking timeless gambles. To see this, let us consider a lottery on a sequence $\left(C_{t+h}\right), h \geq 0$, of current and future consumption that is genuinely timeless because the two following conditions are fulfilled. First, randomness is about just one particular future consumption $\left(C_{t+H}\right)$ for given $H$, while the other ones are known at time $t$. For sake of notational simplicity, let us assume that for any $h \neq H, C_{t+h}=$ $C^{*}$ given. Second, the uncertainty at time $t$ about $C_{t+H}$ has no temporal features. Basically, the value of $C_{t+H}$ appears to be random at time $t$ but is going to be known no later than time $(t+1)$.

\footnotetext{
${ }^{2}$ See Becker and Boyd III (1997) for a review of aggregators and their properties.
} 
Then, with the aggregator (2.2), the utility index $V_{t}$ at time $t$ is given by:

$$
V_{t}=u\left(C^{*}\right)+\beta m\left[(1-\beta)^{-1} u\left(C^{*}\right)+\beta^{H-1}\left\{u\left(C_{t+H}\right)-u\left(C^{*}\right)\right\}\right]
$$

We deduce from (2.5) that it is true that $m$ characterizes the risk aversion preferences for timeless gambles. Typically, for a given level of risk involved in future consumption $C_{t+H}$, different people will value more or less such a gamble depending upon their level of risk aversion included in $m$ or, equivalently, in the Von Neumann-Morgenstern utility index $f$.

This risk aversion assessment appears at first sight to be fairly well disentangled from the other features of preferences since the rate of time preference and the elasticity of intertemporal substitution, as described respectively by $\beta$ and the function $u$, do not play an important role in this argument. Of course, the risk exposure is not assessed directly in terms of consumption units $C_{t+H}$, but only through its concave transformation $u\left(C_{t+H}\right)$. Yet, no genuinely perverse effect results form this concave scaling.

However, if one thinks about more general temporal gambles, it is no longer true that, as commonly believed, $m$ and $f$ will determine the degree of risk taking in portfolio choice problems. We argue that the disentangling of risk aversion and intertemporal substitution is not fully done in the recursive utility framework (2.3) and (2.4). To explain this intuitively, we will rely on the analysis of Alvarez and Jermann (2000), who establish a clear distinction between the related concepts of equity premium and cost of consumption uncertainty. The marginal cost of consumption uncertainty is defined, as we did above, from the time $t$ return until maturity of an asset with a single risky payment $C_{t+H}$ at $(t+H)$. However, the consumption equity premium (for an equity with dividends equal to consumption) is defined from the time $t$ shadow price of an asset which pays the full stochastic process of dividends $[C]=\left[C_{t+h}, h \geq 0\right]$. In order to control for preferences for the timing of uncertainty resolution, let us maintain the assumption that all uncertainty about this process is revealed at time $(t+1)$. Then the relevant utility index is:

$$
V_{t}=u\left(C_{t}\right)+\beta m\left[\sum_{h=1}^{\infty} \beta^{h-1} u\left(C_{t+h}\right)\right]
$$

Assume for simplicity that $\beta=1$ and that the stochastic process $\left[C_{t+h}, h>0\right]$ is stationary and ergodic. Then, the higher the elasticity of intertemporal substitution featured by the function $u$ is, the more the individual is able to consider the stochastic process $\left[C_{t+h}, h>0\right]$ as almost equivalent to its smoothed counterpart $\left[C_{t+h}^{*}, h>0\right]$ defined by:

$$
C_{t+h}^{*}=\lim _{H=\infty}\left(\frac{1}{H}\right) \sum_{j=1}^{H} C_{t+j}
$$


But, by the law of large numbers, the smoothed consumption process is no longer risky. In other words, a high elasticity of intertemporal substitution allows one to think in terms of intertemporal diversification and substantially lowers the level of risk which is significantly borne in a formula like (2.6). The argument could of course be easily extended to more realistic situations of consumption processes with trends and non zero rate of time preference.

This remark is of course highly relevant when it comes to solving the equity premium puzzle since it implies that $m$ does not provide a meaningful assessment of the individual risk aversion. In other words, one cannot claim to have successfully solved the puzzle when a reasonable level of risk aversion (as described by $m$ or $f$ ) is obtained in a representative agent model consistent with (2.3) and (2.4). It may only mean that risk aversion has been underestimated through its $m$ (or $f$ ) characterization since the agent, with a sufficiently high elasticity of intertemporal substitution, might have perceived that the risk was not so high because of temporal diversification.

This possibility of temporal diversification explains that, as acknowledged by Duffie and Epstein (1992, a ,b), the significance of the function $m$ for comparative risk aversion arises only for a given elasticity of intertemporal substitution. Our argument goes further though. It would be illusory to rely on a plausible estimate of the risk aversion coefficient in an Epstein-Zin model of asset prices to consider that the equity premium puzzle has been solved. It all depends on the value of the elasticity of intertemporal substitution. The higher it is, the more spurious the inference will be. Following Alvarez and Jermann (2000), this amounts to confuse the equity premium and the cost of consumption uncertainty even though they are clearly distinct, both conceptually and quantitatively. They argue that the steepness of the term structure and the persistence of the shocks are two of the features that make the equity premium different from the marginal cost of consumption uncertainty.

We will propose in the next subsection an expected utility functional form which explicitly takes into account the degree of persistence of the shocks. For this reason, it is better able to disentangle risk aversion from the elasticity of intertemporal substitution. Actually, we derive an asset pricing model which is observationally equivalent to the one of Epstein and Zin (1989) but which modifies the definition of the risk aversion measurement in order to avoid the aforementioned shortcoming of recursive utility, that is the underestimation through $m$ of the true level of risk aversion when the elasticity of intertemporal substitution is high.

Another advantage of our expected utility model is that it only refers to an individual who is neutral with respect to the timing of uncertainty resolution. Indeed, in addition to the temporal aspects of preferences, captured by $\beta$ and the function $u$, and the risk 
aversion measure given by $m$, a third aspect of preferences should concern the timing of resolution of uncertainty. Actually, if in the above example we assume now that the risky consumption flow $C_{t+H}, H \geq 2$, is going to be revealed only at time $(t+2)$, we realize that the utility index at time $t$ is different from (2.5). In other words, the definition of $(\beta, u, m)$ characterizes the conditions under which early or late resolution is preferred. Thus, as recognized by Epstein and Zin (1989), this "latter aspect of preferences seems intertwined with both substitutability and risk aversion". While they suspect that this "reflects the inherent inseparability of these three aspects of preference rather than a deficiency" of the framework, the new model proposed in the next section will give more support to the requirement of disentangling preferences for the timing of uncertainty resolution from substitutability and risk aversion. In contrast with Epstein and Zin (1989), this aspect of preferences does no longer seem implied by the comparison of disentangled levels of elasticity of intertemporal substitution and risk aversion. Therefore, one can envision a more general model which would not only disentangle risk aversion from intertemporal substitution, but also describe independently the timing of uncertainty resolution.

\section{A Consumption CAPM with a Reference Level}

In GRS (2002), we develop an intertemporal expected utility model where the representative agent derives utility from consumption measured relatively to a reference level and from this reference level itself:

$$
V_{t}=[\lambda(1-a)] \sum_{h=o}^{\infty} \delta^{h} E_{t}\left\{\left[\frac{C_{t+h}}{S_{t+h}}\right]^{1-a}\left[S_{t+h}\right]^{\lambda}\right\}
$$

where the reference level $S_{t}$ is considered as external to the agent and $E_{t}$ denotes a conditional expectation given the information at time $t$. Depending on the specification of the reference level and on the constraints imposed on the various preference parameters, we show in GRS (2002) that this model produces most of the SDFs that have been used in the empirical asset pricing literature. We will now see how it should be modeled to obtain a SDF which is observationally equivalent to the one derived by Epstein and Zin (1989).

Our argument rests essentially on the fact that the reference level provides a way to extend intertemporal choice of consumption without uncertainty to risky consumption streams. When no uncertainty prevails, the future sequence of the reference level at time t, $S_{t+h}, h \geq 0$, coincides with the optimal future consumption values:

$$
S_{\bar{t}+h}=C_{t+h} \text { identically for } h \geq 0
$$


In a risky environment, we just generalize condition (3.2) in terms of conditional expectations:

$$
E_{t}\left[S_{t+h}\right]=E_{t}\left[C_{t+h}\right] \text { for all } h \geq 0
$$

Therefore, we can interpret $S_{t+h}$ as the reference level the agent has in mind at time $t$ to decide his risk-taking behavior. In the spirit of Abel (1990) and Campbell and Cochrane (1999) models of external habit formation, some macroeconomic variables which belong to the agent's information set at time $(t+h)$ may affect the assessment of the reference level $S_{t+h}$. In the model of Barberis, Huang and Santos (2001), when the representative agent's consumption $C_{t+h}$ coincides in equilibrium with the $\bar{C}_{t+h}$ aggregate per capita consumption at time $(t+h)$ (viewed as exogenous to the investor), the reference level of consumption will integrate the gain or loss the agent experiences on his financial investments between $(t+h-1)$ and $(t+h)$. In all these examples, the growth rate $\frac{S_{t+h}}{S_{t+h-1}}$ of benchmark consumption between dates $(t+h-1)$ and $(t+h)$ may include some information contemporaneous with $C_{t+h} \cdot^{3}$

Given condition (3.2), the parameter $\lambda$ in (3.1) can unambiguously be interpreted in terms of intertemporal elasticity of substitution, with $\lambda=1-\frac{1}{\xi}$, where $\xi$ denotes the agent's elasticity of intertemporal substitution. Since the reference level is viewed as external by the agent during his optimization, the resulting Euler conditions lead to a generalized CCAPM with the following SDF:

$$
M_{t+1}=\delta\left[\frac{C_{t+1}}{C_{t}}\right]^{-a}\left[\frac{S_{t+1}}{S_{t}}\right]^{a-\frac{1}{\xi}} .
$$

Such a SDF implies that the definition of the reference level must produce conditional expectations that are not only constrained by (3.3), but also consistent with the observed asset prices.

Let us consider first the market portfolio pricing condition. If we denote by $R_{M, t+1}$ the return on the market portfolio observed at time $(t+1)$, we get:

$$
E_{t}\left\{\delta\left[\frac{C_{t+1}}{C_{t}}\right]^{-a}\left[\frac{S_{t+1}}{S_{t}}\right]^{a-\frac{1}{\xi}} R_{M, t+1}\right\}=1
$$

\footnotetext{
${ }^{3}$ Campbell and Cochrane (1999) also specify that the consumption habit moves in response to current aggregate consumption and not, as in many habit formation models, in proportion to the last period consumption. Since habit is considered as external, the reference level $S_{t+h}$ may even be defined as a function of $C_{t+h}$.
} 
Condition (3.5) shows that covariation between the reference level and the market return may compensate for the lack of covariation between consumption and the market return. This extension of the traditional consumption-based asset pricing model may help to solve several asset pricing puzzles features associated with aggregate data. As stressed by Barberis, Huang and Santos (2001), such an extension has some behavioral foundations since it captures the idea that the degree of loss aversion of the investor depends on his prior investment performance. To make even more explicit this tight relationship between the reference level and investment performance as measured by the market return, we will refer to a log-linerization of conditional moment restrictions (3.3) and (3.5) (see Epstein and Zin (1991) and Campbell (1993) for similar interpretations based on a log-linearization of the Euler equations). Conditional expectations are computed as if the vector:

$$
\left(\Delta c_{t+1}, \Delta s_{t+1}, r_{M, t+1}\right)=\left(\log \left[\frac{C_{t+1}}{C_{t}}\right], \log \left[\frac{S_{t+1}}{S_{t}}\right], \log R_{M, t+1}\right)
$$

were jointly normal and homoskedastic given the information available at time $t$. Conditions (3.3) and (3.5) at horizon 1 become:

$$
\begin{aligned}
E_{t}\left[\Delta c_{t+1}\right]-E_{t}\left[\Delta s_{t+1}\right] & =\kappa_{1} \\
-a E_{t}\left[\Delta c_{t+1}\right]+\left(a-\frac{1}{\xi}\right) E_{t}\left[\Delta s_{t+1}\right]+E_{t}\left[r_{M, t+1}\right] & =\kappa_{2}
\end{aligned}
$$

for some constants $\kappa_{1}$ and $\kappa_{2}$. Equivalently, these two restrictions say that both $\left[\Delta s_{t+1}-\right.$ $\left.\Delta c_{t+1}\right]$ and $\left[\Delta s_{t+1}-\xi r_{M, t+1}\right]$ must be unpredictable at time $t$. We will now see that the Epstein and Zin (1989) pricing model is observationally equivalent to the particular case of our CCAPM with reference level where $\left[\Delta s_{t+1}-\xi r_{M, t+1}\right]$ is not only unpredictable but constant:

$$
\log \frac{S_{t+1}}{S_{t}}=\xi \log R_{M, t+1}+\kappa,
$$

for some constant $\kappa$. In other words, we consider the particular case where the benchmark growth rate of consumption is log-linearly determined by the current value of the market return, with a slope parameter equal to the elasticity of intertemporal substitution. Note that this is in accordance with the portfolio separation property generally implied by homotheticity of preferences (see Epstein and Zin, 1989), whereby optimal consumption is determined in a second stage, after the portfolio choice has been made.

Given the specification (3.8) of the reference level, it is clear that the parameters $\delta$ and $\kappa$ cannot be separately identified from this SDF only. We will therefore reparametrize it in the following way: 


$$
M_{t+1}=\beta\left[\frac{C_{t+1}}{C_{t}}\right]^{-a}\left[R_{M, t+1}\right]^{a \xi-1} .
$$

At first sight, we obtain a SDF which is observationally equivalent to the one derived by Epstein and Zin (1989) with the TAS aggregator, with some utility function $u$ and a von Neumann-Morgenstern utility index $f$ which are both isoelastic. Yet there are several important differences in the interpretation of the two SDFs.

Let us start with the market return which enters both SDF specifications. In our model, it appears because the investor links the benchmark consumption to the market return. In the recursive utility framework, it appears because the investor cares about the timing of uncertainty resolution. Actually, in (3.1), the utility index is defined in terms of conditional expectations of future random variables given the information available at time $t$, and therefore, the investor appears to be neutral with respect to the timing of uncertainty resolution. In this respect, our approach is closer to Bakshi and Chen (1996) who put forward the hypothesis that investors accumulate wealth not only for the sake of consumption but also for wealth-induced social status. Typically, if the reference level $S_{t}$ were equal to aggregate wealth, a non-zero difference between $\lambda$ and $(1-a)$ would lead to Model 1 of Bakshi and Chen (1996) where absolute wealth is status. This explains why Bakshi and Chen (1996) also put forward a kind of observational equivalence between their model and Epstein and Zin (1989). However, our approach does not reduce to theirs because they implicitly consider that the rate of growth of aggregate wealth coincides with the market return, which is not true in general. They differ because the share of wealth invested is not constant ${ }^{4}$. On the contrary, Lettau and Ludvigson (2001) have emphasized the prominent role played by the consumption-wealth ratio as a state variable to summarize the relevant conditioning information.

Actually, our model is better understood by reference to the habit formation literature. Our agent derives utility both from the level of consumption relative to the state variable $S_{t}$ and from the absolute value of this reference level which is similar to a habit. This specification extends to asset pricing applications the one recently used in a saving and growth model by Carroll, Overland and Weil (2000). In the spirit of the habit formation literature, the coefficient $a$ is then interpreted as the risk aversion coefficient. This interpretation immediately raises the following question. Since the SDF (3.9) is observationally equivalent

\footnotetext{
${ }^{4}$ Bakshi and Chen (1996) can be interpreted as a particular case of our model with a unit elasticity of intertemporal substitution. Smith (2001) proposes to extend Bakshi and Chen (1996) by taking into account both the concern about wealth-induced status and the attitude towards the timing of uncertainty resolution. However, it is a simple i.i.d. economy in which the stochastic variation in the invested share of wealth cannot be accomodated.
} 
to the one of Epstein and Zin (1989) with isoelastic functions $u$ and $f\left(u(C)=\left(\frac{1}{\rho}\right)\left(C^{\rho}-1\right)\right.$ and $\left.f(V)=\left(\frac{1}{\alpha}\right)\left(V^{\alpha}-1\right)\right)$, it should shed some light on the difficult issue of risk aversion assessment in the context of the recursive utility model of Epstein and Zin (1989). Actually, the exponent of $\frac{C_{t+1}}{C_{t}}$ in this model (see equation (6.6) p. 958) is:

$$
\alpha \frac{(\rho-1)}{\rho}=\frac{\alpha}{1-\sigma}, \text { since } \sigma=(1-\rho)^{-1}
$$

By identification of (3.9) and (3.10), we deduce that the quantity $(1-\alpha)$, instead of being interpreted as a risk aversion parameter, should be seen as:

$$
(1-\alpha)=a+1-a \sigma
$$

Several comments are in order. First, the ability of the recursive utility model to disentangle risk aversion and intertemporal substitution is questionable. Actually, it is only in the standard expected utility model case, when $\sigma$ is the inverse of the risk aversion parameter $a$, that $(1-\alpha)$ can be interpreted as a risk aversion parameter. Even more problematic is the fact that $(1-\alpha)$ becomes negative whenever $\sigma$ is greater than $\frac{1}{a}+1$. Note that this lack of disentangling manifests itself even without resorting to our interpretation of $a$ as a risk aversion parameter. The natural requirement of a negative exponent for $\frac{C_{t+1}}{C_{t}}$ in the SDF implies that the alleged risk aversion parameter $(1-\alpha)$ and $\frac{1}{\sigma}$ should be on the same side of 1 .

Second, as soon as $\sigma$ is greater than $\frac{1}{a}$, the alleged risk aversion parameter $(1-\alpha)$ underestimates the genuine risk aversion parameter $a$. Hence, as noted before in Section 2 , a relatively high level of elasticity of intertemporal substitution may spuriously indicate a moderate risk aversion. If, as documented by Mehra and Prescott (1985), the model can replicate the equity risk premium only for a high level of risk aversion, say $a=20$, even a moderate elasticity of substitution, say .8, will dramatically lower the perceived risk aversion in the recursive utility model: $(1-\alpha)=5$.

Of course, expressing concerns about the recursive utility model does not imply that the alternative model we propose is valid. For tests of its empirical validity, we refer the reader to GRS $(2002)^{5}$. However, it is important to stress that, apart from the issues related to the interpretation of risk aversion and the attitude towards the timing of uncertainty

\footnotetext{
${ }^{5}$ We estimate in particular a model where the reference level growth rate is determined both by past consumption growth rates (as in habit formation models) and by the return of the market portfolio (as in the Kreps-Porteus specification of the recursive utility model of Epstein and Zin, 1989). The parameters of this specification are economically plausible and estimated with precision.
} 
resolution, the two models are mutually consistent. Indeed, taking (3.11) into account, we can rewrite the exponent of the market return in the Epstein-Zin SDF as:

$$
\left(\frac{\alpha}{\rho}\right)-1=a \sigma-1
$$

By identification with (3.9), we see that our SDF is nothing but a reparametrization of the Epstein-Zin's one with: $\xi=\sigma$ (and $\lambda=\rho$ ). This coincidence between the parameters of intertemporal substitution of the two models is fully consistent with the interpretation sketched above. It also sheds some interesting light on the issue of myopic portfolio choice. Giovannini and Weil (1989) have stressed that a unit elasticity of intertemporal substitution implies a form of (rational) myopia in consumption and savings decisions but not in portfolio allocation. Actually, a unit elasticity of intertemporal substitution $(\lambda=0)$ reduces our general SDF (3.4) to:

$$
M_{t+1}=\delta\left[\frac{C_{t+1}}{C_{t}}\right]^{-a}\left[\frac{S_{t+1}}{S_{t}}\right]^{a-1} .
$$

and, if one admits the log-linearization $(3.8)^{6}$ :

$$
M_{t+1}=\delta\left[\frac{C_{t+1}}{C_{t}}\right]^{-a}\left(R_{M t+1}\right)^{a-1} .
$$

This formula can be seen as the explicit solution of equation (B.5) in Giovannini and Weil (1989) for the particular case of conditional log-normality. Except for logarithmic risk preferences ( $a=0$ for us and $\alpha=0$ for them), the Euler equations for portfolio choice with $\sigma=1$ correspond in general to neither the static CAPM nor the CCAPM. Giovannini and Weil (1989) develop their argument rigorously but it is hard to do in the orthodox approach of the EZ SDF since one gets the spurious feeling that the exponent of consumption growth in the $\operatorname{SDF}\left(\frac{\alpha}{1-\sigma}\right)$ is well defined and non zero in the limit cases only if one maintains the equivalence: $\sigma=1 \Longleftrightarrow \alpha=0$. This is the equivalence between myopic consumptionsaving decisions and logarithmic risk preferences. This issue is relevant empirically. For instance, Epstein and Zin (1991) conclude that risk preferences do not differ statistically from the logarithmic specification but, by the same token, they find estimates for the elasticity of intertemporal substitution that are not statistically different from 1 for the two first sets of instruments (the ones which, according to the authors, give the most sensible results). Another interesting case is the portfolio applications in Campbell and Viceira (2002). To be able to disentangle myopia in consumption-saving decisions from

\footnotetext{
${ }^{6}$ With or without this log-linearization, this result is fully consistent with the point made by Giovannini and Weil (1989).
} 
myopia in portfolio allocation, they set $\sigma=1$ while allowing any value for the risk aversion parameter. While they are certainly right to do so for economic interpretations, this is strictly speaking not consistent with the EZ parameterization, as it can be seen not only through our interpretation but also through the Appendix B of Giovannini and Weil (1989). By contrast, the exponent $a$ in our $\operatorname{SDF}(3.13,3.14)$ is in no way restricted by the condition $\sigma=1$.

To summarize, the only difference between our approach and the Epstein and Zin (1989) recursive utility model concerns the incorporation of the preferences for intertemporal choice without uncertainty in a risky environment with constant relative risk aversion. While the recursive utility approach replaces the future random utility index by its certainty equivalent, we believe it is preferable to replace upstream the future consumption flows by an external benchmark produced by the first-order conditions for optimal consumption. This benchmark determines the role of the time preference parameters while the risk aversion parameter matters only insofar as uncertainty prevents the agent from meeting his benchmark.

Of course, our argument rests upon some approximations due to a log-linearization of first-order conditions for consumption and neglects volatility predictability. While extensions can be envisioned in this regard, our new insight on risk aversion assessment in the recursive utility model is useful for addressing asset pricing puzzles. In terms of risk premium for individual assets, log-linearization of the pricing equations resulting from our SDF gives:

$$
E_{t}\left[r_{i, t+1}\right]-r_{f, t+1}=a \sigma_{i c}-(a \sigma-1) \sigma_{i m}
$$

where $\sigma_{i c}$ and $\sigma_{i m}$ denote the covariances of asset $i$ returns with consumption growth and market returns respectively. This asset pricing model is observationally equivalent to the one of Epstein and Zin (1989) but the interpretation of the coefficients and their orders of magnitude deemed to be reasonable differ. The coefficient of $\sigma_{i c}$ should be interpreted as a risk aversion parameter, which means, in particular, that it is constrained to be nonnegative. Following the recursive utility parametrization, this would not be the case since $a=(1-\sigma)^{-1}\left(a^{*}-1\right)$, where $a^{*}=(1-\alpha)$ is the risk aversion measure. In addition, the coefficient of $\sigma_{i m}$ is $(a \sigma-1)=(1-\sigma)^{-1}\left(a^{*} \sigma-1\right)$, which can take very large values for seemingly realistic values of the coefficient $a^{*}$. 


\section{Conclusion}

In this paper, we have proposed a generalized expected utility framework which disentangles risk aversion and intertemporal substitution in an alternative way to the recursive utility framework proposed by Epstein and Zin (1989). Although observationally equivalent, the two models may lead to significantly different conclusions regarding the well-documented asset pricing puzzles. In particular, a plausible value of the elasticity of intertemporal substitution smaller than one, but not too close to zero, can conceal, within a recursive utility framework, a very large implied value for risk aversion.

One of the advantages of our specification is its flexibility. In GRS (2002), we show that it can reproduce most of the SDFs that have been proposed in the empirical asset pricing literature. In particular, it covers all habit formation approaches and can be seen as a generalization of Campbell and Cochrane (1999). As in the latter, a key assumption is to assume that the reference level is exogenous to the agent. When the growth rate of the reference level is made a function of the return on the market portfolio we obtain a SDF which is observationally equivalent to the Kreps and Porteus certainty equivalent in the recursive utility framework. Other specifications of the certainty equivalent, in particular disappointment aversion, can also be accommodated in our framework given the right specification of the reference level (see GRS, 2002). The simplicity of our expected utility approach makes it a serious contender for the more involved recursive utility specifications. Moreover, it allows to specify new SDFs which can potentially better explain asset prices. In GRS (2002), we propose a new SDF based on habit persistence and the return on the market portfolio which appears to be supported by the data.

Our generalized expected utility framework basically maintains the assumption of investor neutrality with regard to the timing of uncertainty resolution. Yet, as emphasized by Kreps and Porteus (1979), temporal preference for consumption is only an induced preference. Is earlier resolution of uncertainty better simply because it permits an adaptive choice of the individual activities or do individual preferences for consumption streams include a genuine subjective preference for earlier or later uncertainty resolution? A more general equilibrium model could then justify embedding our Von Neumann- Morgenstern utility with respect to a reference level into a recursive framework with a clear formulation of the timing of outcomes of lotteries and resulting actions taken by the agent. Such a model might provide an answer to the question raised by Epstein and Zin (1989): is there some inherent inseparability of the three aspects of preferences: risk aversion, intertemporal substitution and concern for the timing of uncertainty resolution? This paper might have provided a first step in finding an answer by a better disentangling of risk aversion 
from intertemporal substitution without any implication about preference for earlier or later resolution of uncertainty.

\section{References}

[1] Abel, A. (1990), "Asset Prices under Habit Formation and Catching Up with the Joneses," The American Economic Review, 80, Papers and Proceedings 38-42.

[2] Abel, A. (1996), "Risk Premia and Term Premia in General Equilibrium," unpublished paper, University of Pennsylvania.

[3] Alvarez, F. and U.J. Jermann (2000), "Using Asset Prices to Measure the Cost of Business Cycles," NBER Working Paper 7978.

[4] Aschauer, D. (1985), "Fiscal Policy and Aggregate Demand," American Economic Review 75, 117-127.

[5] Bakshi, G. and Z. Chen (1996), "The Spirit of Capitalism and Stock-Market Prices," American Economic Review 86, 133-157.

[6] Barberis, N., M. Huang, and T. Santos (2001), "Prospect Theory and Asset Prices," Quarterly Journal of Economics 116, 1-53.

[7] Becker, R. and J. Boyd III (1997), "Capital Theory, Equilibrium Analysis and Recursive Utility," Blackwell Publishers.

[8] Campbell, J. (1993), "Intertemporal Asset Pricing without Consumption Data," American Economic Review 83, 487-512.

[9] Campbell, J. and J. Cochrane (1999), "By Force of Habit: A Consumption-Based Explanation of Aggregate Stock Market Behavior," Journal of Political Economy 107, 205-251.

[10] Campbell, J. and L. Viceira (2002), Strategic Asset Allocation, Portfolio Choice for Long-Term Investors, Clarendon Lectures in Economics, Oxford University Press.

[11] Carroll, C., J. Overland, and D. Weil (2000), "Saving and Growth with Habit Formation", The American Economic Review 90, 341-355.

[12] Constantinides, G. (1990), "Habit Formation: A Resolution of the Equity Premium Puzzle," Journal of Political Economy 98, 519-543. 
[13] Duffie, D. and L. G. Epstein (1992a), "Stochastic Differential Utility," Econometrica $60(2), 353-394$.

[14] Duffie, D. and L. G. Epstein (1992b), "Asset Pricing with Stochastic Differential Utility," The Review of Financial Studies 5(3), 411-436.

[15] Eichenbaum, M., L. Hansen, and K. Singleton (1988), "A Time Series Analysis of Representative Agent Models of Consumption and Leisure Choice under Uncertainty", Quarterly Journal of Economics 103, 51-78.

[16] Epstein, L. and S. Zin (1989), "Substitution, Risk Aversion, and the Temporal Behavior of Consumption and Asset Returns: A Theoretical Framework," Econometrica 57, 937-969.

[17] Epstein, L. and S. Zin (1991), "Substitution, Risk Aversion, and the Temporal Behavior of Consumption and Asset Returns I: An Empirical Analysis," Journal of Political Economy 99, 263-286.

[18] Garcia, R., E. Renault and A. Semenov (2002), "A Consumption Capital Asset Pricing Model with A Reference Level," working paper, CIRANO and Université de Montréal.

[19] Giovannini, A. and P. Weil (1989), "Risk Aversion and Intertemporal Substitution in the Capital Asset Pricing Model," NBER Working Paper No. 2824, National Bureau of Economic Research, Cambridge, MA.

[20] Guvenen, F. (2002), "Habit Formation or Cross-sectional Heterogeneity?," working Paper, University of Rochester.

[21] Koopmans, T. (1960), "Stationary Ordinal Utility and Impatience," Econometrica 28, 287-309.

[22] Kreps, D. and E. Porteus (1978), "Temporal Resolution of Uncertainty and Dynamic Choice Theory," Econometrica 46, 185-200.

[23] Kreps, D. and E. Porteus (1979), "Temporal von Neumann-Morgenstern and Induced Preferences," Journal of Economic Theory 20, 81-109.

[24] Lettau, M. and S. Ludvigson (2001), "Resurrecting the (C)CAPM: A Cross-Sectional Test When Risk Premia Are Time-Varying", Journal of Political Economy 109, 12381287. 
[25] Lucas, R. and N. Stokey (1984), "Optimal Growth with Many Consumers," Journal of Economic Theory, 32, 139-171.

[26] Mehra, R. and E. C. Prescott (1985), "The Equity Premium: A Puzzle", Journal of Monetary Economics 15, 145-61.

[27] Smith, W. (2001), "How Does the Spirit of Capitalism Affect Stock Market Prices?," Review of Financial Studies, 14: 1215-1232.

[28] Startz, R. (1989), "The Stochastic Behavior of Durable and Non-Durable Consumption," Review of Economics and Statistics 71, 356-363.

[29] Sundaresan, S. (1989), "Intertemporally Dependent Preferences and the Volatility of Consumption and Wealth," Review of Financial Studies 2, 73-88.

[30] Weil, P. (1989), "The Equity Premium Puzzle and the Risk-Free Rate Puzzle," Journal of Monetary Economics 24, 401-421.

[31] Weil, P. (1990), "Non-Expected Utility in Macroeconomics," Quarterly Journal of Economics 105(1), 29-42. 